\title{
Article
}

\section{Changes in Sleep Patterns and Disorders in Children and Adolescents with Attention Deficit Hyperactivity Disorders and Autism Spectrum Disorders during the COVID-19 Lockdown}

\author{
Oliviero Bruni ${ }^{1, *(\mathbb{C}}$, Maria Breda $^{2}\left(\mathbb{D}\right.$, Raffaele Ferri $^{3}\left[{ }^{-}\right.$and Maria Grazia Melegari ${ }^{1,4}$ \\ 1 Department of Developmental and Social Psychology, Sapienza University, 00185 Rome, Italy; \\ mgraziamelegari@gmail.com \\ 2 Child Neurology and Psychiatry Unit, Department of Human Neurosciences, Sapienza University, \\ 00185 Rome, Italy; maria.breda@uniroma1.it \\ 3 Sleep Research Centre, Department of Neurology IC, Oasi Research Institute—IRCCS, 94018 Troina, Italy; \\ rferri@oasi.en.it \\ 4 Consortium “Humanitas" LUMSA University, 00193 Rome, Italy \\ * Correspondence: oliviero.bruni@uniroma1.it; Tel.: +39-335-607-8964
}

check for

updates

Citation: Bruni, O.; Breda, M.; Ferri, R.; Melegari, M.G. Changes in Sleep Patterns and Disorders in Children and Adolescents with Attention Deficit Hyperactivity Disorders and Autism Spectrum Disorders during the COVID-19 Lockdown. Brain Sci. 2021, 11, 1139. https://doi.org/ 10.3390/brainsci11091139

Academic Editor: Roumen Kirov

Received: 29 July 2021

Accepted: 25 August 2021

Published: 27 August 2021

Publisher's Note: MDPI stays neutral with regard to jurisdictional claims in published maps and institutional affiliations.

Copyright: (c) 2021 by the authors. Licensee MDPI, Basel, Switzerland. This article is an open access article distributed under the terms and conditions of the Creative Commons Attribution (CC BY) license (https:// creativecommons.org/licenses/by/ $4.0 /)$.

\begin{abstract}
Background. The COVID-19 lockdown determined important changes in the sleep of a large percentage of the world population. We assessed the modifications of reported sleep patterns and disturbances in Italian children and adolescents with autism spectrum disorders (ASD) or attention deficit hyperactivity disorders (ADHD), compared to control children, before and during the COVID-19 lockdown in Italy. Methods. Parents of 100 ASD, 236 ADHD patients, and 340 healthy children filled out an anonymous online survey and a modified version of the Sleep Disturbance Scale for Children (SDSC), advertised via social media, to evaluate sleep patterns and disturbances of their children before and during the lockdown. Results. Before the lockdown, bedtime and risetime were not different between the three groups. During the lockdown, ADHD children tended to have a later bedtime and risetime than ASD and controls, while ASD children tended to maintain similar bedtime and risetime. Overall, during the lockdown, a reduced sleep duration significantly differentiated clinical groups from controls. Anxiety at bedtime, difficulties in falling asleep, and daytime sleepiness increased in all groups during the lockdown. Hypnic jerks, rhythmic movement disorders, night awakenings, restless sleep, sleepwalking, and daytime sleepiness increased in ASD and ADHD patients, in particular. Conclusions. This is the first study comparing sleep habits and disorders in ASD and ADHD during the lockdown showing specific differences consistent with the core characteristics of two neurodevelopmental disorders.
\end{abstract}

Keywords: sleep; ADHD; ASD; COVID-19

\section{Introduction}

The general confinement from the COVID-19 pandemic and the consequent school closure, interruption of contacts with family members and friends, as well as reduced social and leisure activities, has brought unparalleled modifications to the lifestyle of children and adolescents, with important repercussions on their mental state and behaviors [1].

In particular, COVID-19 lockdown resulted in important changes in sleep habits and sleep disorders in a large portion of the world's population of all ages [2-6]. The increase in sleep difficulties was often associated with higher levels of psychopathological symptoms or decreased quality of life [3,7,8].

In face of a great amount of literature on the young and adult general population, only a few studies were conducted on sleep patterns or disturbances of the clinical population, especially children and adolescents with autism spectrum disorder (ASD) [9] and attentiondeficit/hyperactivity and impulsive disorders (ADHD) [10], despite their frequent sleep disturbances and altered sleep patterns, independently by COVID-19 [11]. Since sleep 
patterns significantly changed during the lockdown in typically developing children and adolescents $[2,5,6,12]$, similar or even worse changes in subjects with ADHD and ASD could be expected. Several studies $[9,10,13-17]$ reported a high percentage of patients with ASD or ADHD that changed their sleep with a significant worsening of sleep quality and disturbances during the lockdown. Specifically, ASD children showed significant worsening of sleep disturbances, sleep duration, and sleep quality $[14,15]$ and an increase in bedtime resistance, delay in falling asleep, and night awakenings [17]. Children with ADHD showed an alteration of sleep patterns in $85 \%$ of cases [16] and, unlike their healthy peers in the control group that experienced an increase in school night sleep duration, they did not benefit from the COVID-19 lockdown [13].

Significant changes in sleep habits and disturbances in children with ADHD or ASD and adolescents during the lockdown have been reported by other studies. Since ADHD and ASD are two neurodevelopmental disorders with different symptoms, we could have expected that sleep changes would reflect specific clinical traits characterizing these two populations. To the best of our knowledge, no study has compared these two disorders for their sleep patterns and disturbances during the COVID-19 lockdown, thus, the aim of this study was to evaluate the different responses of these two clinical conditions in terms of sleep patterns and sleep disturbances.

\section{Materials and Methods}

\subsection{Participants}

Parents of Italian children and adolescents completed an online survey, advertised via social media, for a limited time window (from 7th May to 15th June 2020), targeting children aged 4 to 18 years. ASD and ADHD children and adolescents had been diagnosed by a child and adolescent psychiatrist of the Child and Adolescent Mental Health Services, before the survey, and were being followed at the same center. The survey was developed and conducted following the guidelines set by the Checklist for Reporting Results of Internet E-Surveys (CHERRIES) [18]. From a total of 5825 respondents, we identified ADHD and ASD patients and selected randomly a sample of typically developing subjects matched for age and sex with the clinical groups.

In total, $100 \mathrm{ASD}$ ( 16 females, $16 \%$ and 84 males, $84 \%$ ), 236 ADHD patients ( 44 females, $18.6 \%$ and 192 males, $81.4 \%$ ), and 340 controls (58 female, $17.1 \%$ and 282 males, $82.9 \%$ ) were enrolled in the analysis.

In Italy, the COVID-19 lockdown started on March 2020 with important restrictions that included school closure, limited activities for businesses and factories, and movement restrictions. The strict lockdown in Italy lasted for almost three months, with the progressive reopening of several activities in mid-June 2020. Italian schools reopened in September 2020, with some limitations.

There was no monetary or credit compensation for participating in the study. The study protocol was approved by the Ethics Committee of the Department of Developmental and Social Psychology of the Sapienza University of Rome and was conducted in accordance with the Declaration of Helsinki.

\subsection{Measures}

A specific questionnaire was arranged for the survey. The first section was devoted to the collection of demographic data (age, gender, caregiver education, region of Italy). A second section was organized to gather information on sleep arrangement and schedule during weekdays and during weekends (bedtime, risetime, sleep latency, sleep duration, co-sleeping). All these questions were asked in order to evaluate differences between before and during the lockdown period. A third section of the survey was related to family composition, work of parents during the lockdown, online lessons for children and adolescents, screen exposure time (excluding the hours for lessons), use of over-the-counter or prescription drugs for sleep. Caregivers completed a modified version of the Sleep Disturbance Scale for Children (SDSC) [19]. 
Retrospective questions were used to estimate perceived changes across two time periods: from "before the lockdown" (i.e., in the last month before the outbreak) to "during the lockdown" (i.e., in the seven days prior to filling out the survey).

The SDSC was originally validated on a sample of 6- to 16-year-old healthy children from the general population [19] but was also used for younger children [20,21]. We grouped questions related to sleep-disordered breathing into one question and selected, in total, 13 items in order to facilitate the compilation by parents.

\subsection{Data Analysis}

Descriptive statistics were applied to characterize sociodemographic variables, sleep patterns, and sleep disturbances. Data were reported as frequencies and percentages for comparisons between the groups. The McNemar's test was performed to compare sleep patterns and sleep disturbances before and during the lockdown. "Before-during" bedtime and risetime were recorded within three categories based if maintained, delayed, or anticipated and sleep duration if maintained, increased, or reduced. Chi-square tests were conducted to compare changes in sleep patterns, sleep schedule, and sleep disturbances before and during lockdown, within and between the groups. Fisher's exact test was applied when appropriate.

For all comparisons, $p$-values less than 0.05 were considered to be statistically significant. Statistical analyses were performed using the SPSS software release 17.0 (SPSS INC, Chicago, IL, USA).

\section{Results}

Demographics of the sample are reported in Table 1.

Table 1. Demographics of the three groups of children enrolled in this study.

\begin{tabular}{|c|c|c|c|}
\hline Gender & ADHD & ASD & Controls \\
\hline Total & 236 & 100 & 340 \\
\hline \multicolumn{4}{|l|}{ Gender } \\
\hline $\mathrm{F}$ & $44(18.6 \%)$ & $16(16.0 \%)$ & $58(17.1 \%)$ \\
\hline M & $192(81.4 \%)$ & $83(83.0 \%)$ & $282(82.9 \%)$ \\
\hline \multicolumn{4}{|l|}{ Age } \\
\hline $4-5$ years & $23(9.7 \%)$ & $24(24.0 \%)$ & $57(16.8 \%)$ \\
\hline $6-12$ years & $155(65.7 \%)$ & $47(47.0 \%)$ & $192(56.5 \%)$ \\
\hline $13-18$ years & $58(24.6 \%)$ & $29(29.0 \%)$ & $91(26.8 \%)$ \\
\hline \multicolumn{4}{|l|}{ Respondent } \\
\hline Mother & $221(93.6 \%)$ & $91(91.0 \%)$ & $315(92.6 \%)$ \\
\hline Father & $14(5.9 \%)$ & $9(9.0 \%)$ & $3(0.9 \%)$ \\
\hline Grandparent & $1(0.4 \%)$ & $0(0.0 \%)$ & $22(6.5 \%)$ \\
\hline \multicolumn{4}{|c|}{ Education level of respondent } \\
\hline Graduation & $79(33.6 \%)$ & $41(41.0 \%)$ & $169(49.9 \%)$ \\
\hline High schools & $123(52.3 \%)$ & $49(49.0 \%)$ & $142(41.9 \%)$ \\
\hline Middle schools & $27(11.5 \%)$ & $9(9.0 \%)$ & $26(7.7 \%)$ \\
\hline Elementary schools & $6(2.6 \%)$ & $1(1.0 \%)$ & $2(0.6 \%)$ \\
\hline \multicolumn{4}{|l|}{ Family income } \\
\hline Low & $45(19.2 \%)$ & $17(17.0 \%)$ & $45(13.5 \%)$ \\
\hline Middle & $183(78.2 \%)$ & $79(79.0 \%)$ & $258(77.2 \%)$ \\
\hline High & $6(2.6 \%)$ & $4(4.0 \%)$ & $31(9.3 \%)$ \\
\hline \multicolumn{4}{|l|}{ Siblings } \\
\hline Only child & $80(34.0 \%)$ & $38(38.4 \%)$ & $86(25.3 \%)$ \\
\hline 2 children & $128(54.5 \%)$ & $45(45.5 \%)$ & $191(56.2 \%)$ \\
\hline 3 children & $24(10.2 \%)$ & $14(14.1 \%)$ & $51(15.0 \%)$ \\
\hline$\geq 4$ children & $3(1.3 \%)$ & $2(2.0 \%)$ & $12(3.5 \%)$ \\
\hline
\end{tabular}


In all three groups, there was a prevalence of males. Most of the parents providing data on their child's sleep habits were mothers and most families had a middle income.

\subsection{Comparison of Sleep Patterns in the Three Groups before and during Lockdown}

\subsubsection{Bedtime}

Before lockdown, no differences were found for bedtime during weekdays in the three groups. During lockdown, no differences were found between the two clinical groups, but the ADHD group that had a higher percentage of children going to bed after $12 \mathrm{a}$.m. than controls and the ASD group had a lower percentage of children going to bed between 10 to 11 p.m. than controls (Table 2; Figure 1).

Table 2. Comparison between bedtime in weekdays before and during lockdown in the three groups.

\begin{tabular}{|c|c|c|c|c|c|c|c|c|c|}
\hline & \multirow[b]{2}{*}{ ADHD } & \multirow[b]{2}{*}{ ASD } & \multirow[b]{2}{*}{ Controls } & \multicolumn{2}{|c|}{ ADHD vs. ASD } & \multicolumn{2}{|c|}{ ADHD vs. Controls } & \multicolumn{2}{|c|}{ ASD vs. Controls } \\
\hline & & & & $x^{2}$ & $p$ & $x^{2}$ & $p$ & $x^{2}$ & $p$ \\
\hline \multicolumn{10}{|l|}{$\begin{array}{l}\text { Bedtime WD } \\
\text { before }\end{array}$} \\
\hline$<8$ p.m. & $5(2.1 \%)$ & $1(1.0 \%)$ & $2(0.6 \%)$ & - & NS * & - & NS * & - & NS * \\
\hline 8-9 p.m. & $55(23.3 \%)$ & $15(15.0 \%)$ & $63(18.5 \%)$ & 2.937 & NS & 1.950 & NS & 0.660 & NS \\
\hline 9-10 p.m. & $\begin{array}{c}114 \\
(48.3 \%)\end{array}$ & $59(59.0 \%)$ & $192(56.5 \%)$ & 3.216 & NS & 3.730 & NS & 0.202 & NS \\
\hline 10-11 p.m. & $45(19.1 \%)$ & $19(19.0 \%)$ & $68(20.0 \%)$ & 0.000 & NS & 0.077 & NS & 0.049 & NS \\
\hline 11 p.m.-12 a.m. & $13(5.5 \%)$ & $4(4.0 \%)$ & $13(3.8 \%)$ & - & NS * & 0.918 & NS & - & NS * \\
\hline$>12$ a.m. & $4(1.7 \%)$ & $2(2.0 \%)$ & $2(0.6 \%)$ & - & NS * & - & NS * & - & NS * \\
\hline \multicolumn{10}{|l|}{$\begin{array}{l}\text { Bedtime WD } \\
\text { during }\end{array}$} \\
\hline$<8$ p.m. & $0(0.0 \%)$ & $1(1.0 \%)$ & $0(0.0 \%)$ & - & NS * & - & NS & - & NS * \\
\hline 8-9 p.m. & $11(4.7 \%)$ & $6(6.0 \%)$ & $14(4.2 \%)$ & 0.236 & NS & 0.106 & NS & 0.602 & NS \\
\hline 9-10 p.m. & $48(20.6 \%)$ & $30(30.0 \%)$ & $82(24.3 \%)$ & 3.446 & NS & 1.090 & NS & 1.330 & NS \\
\hline 10-11 p.m. & $73(31.3 \%)$ & $25(25.0 \%)$ & $121(35.9 \%)$ & 1.350 & NS & 1.284 & NS & 4.122 & 0.042 \\
\hline 11 p.m.-12 a.m. & $56(24.0 \%)$ & $26(26.0 \%)$ & $82(24.3 \%)$ & 0.146 & NS & 0.007 & NS & 0.115 & NS \\
\hline$>12$ a.m. & $45(19.3 \%)$ & $12(12.0 \%)$ & $38(11.3 \%)$ & 2.638 & NS & 7.153 & 0.007 & 0.040 & NS \\
\hline
\end{tabular}

$\mathrm{WD}=$ weekday. Significant differences at $p<0.05$ are in bold. * Fisher's exact test was applied.

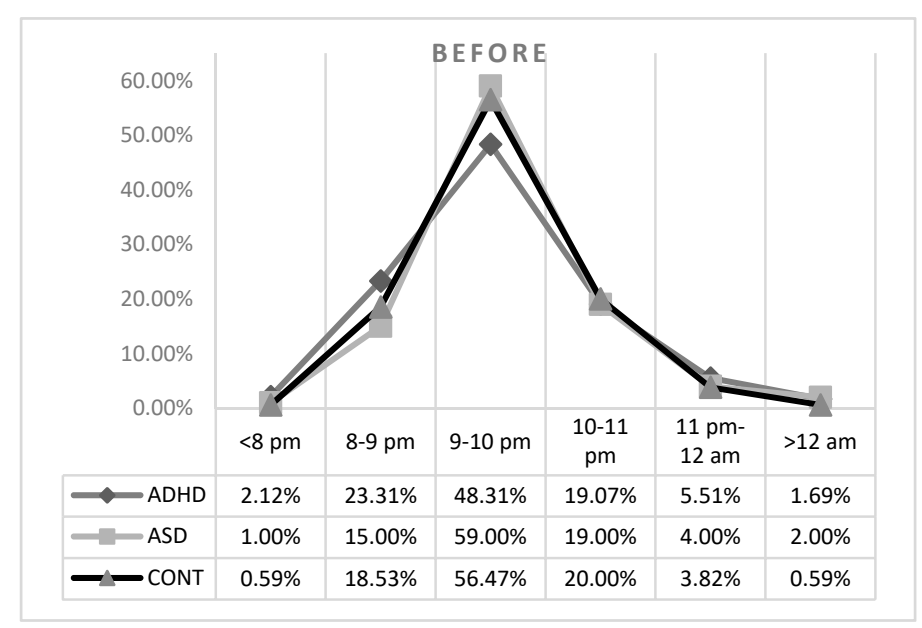

(a)

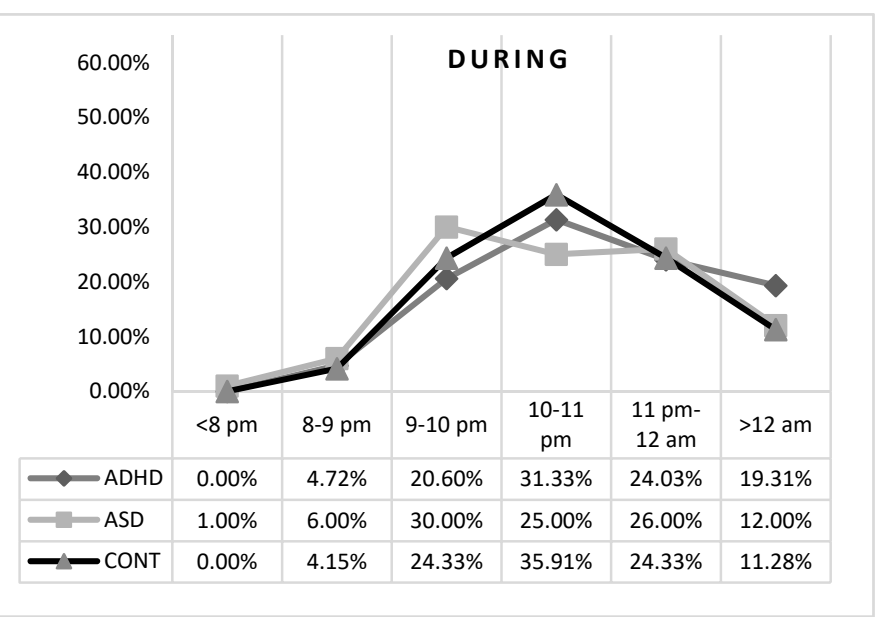

(b)

Figure 1. Bedtime before (a) and during (b) lockdown in the tree groups.

\subsubsection{Risetime}

Similarly, before lockdown, no differences were found for risetime during weekdays, probably due to common school schedules (Table 3; Figure 2). 
During lockdown, the lack of obliged risetime led to the appearance of important differences: $19.6 \%$ of ASD children continued to wake up before 7 a.m., whereas only $6.1 \%$ of ADHD and $4.45 \%$ of the control group stayed in this time slot. Most ADHD children and controls ( $44.8 \%$ and $42.8 \%$, respectively) woke up between 8 and 9 a.m., whereas ASD children's risetime during lookdown was more uniformly distributed in the early morning hours (Table 3; Figure 2). Both clinical groups had a significantly higher percentage of children with risetime after 10 a.m. than controls.

Table 3. Comparison between risetime in weekdays before and during lockdown in the three groups.

\begin{tabular}{|c|c|c|c|c|c|c|c|c|c|}
\hline & \multirow[b]{2}{*}{ ADHD } & \multirow[b]{2}{*}{ ASD } & \multirow[b]{2}{*}{ Controls } & \multicolumn{2}{|c|}{ ADHD vs. ASD } & \multicolumn{2}{|c|}{ ADHD vs. Controls } & \multicolumn{2}{|c|}{ ASD vs. Controls } \\
\hline & & & & $\chi^{2}$ & $p$ & $x^{2}$ & $p$ & $x^{2}$ & $p$ \\
\hline \multicolumn{10}{|c|}{$\begin{array}{l}\text { Risetime WD } \\
\text { before }\end{array}$} \\
\hline$<7$ a.m. & $100(42.6 \%)$ & $36(36.0 \%)$ & $115(33.9 \%)$ & 1.249 & NS & 4.412 & 0.036 & 0.148 & NS \\
\hline 7-8 a.m. & $120(51.1 \%)$ & $53(53.0 \%)$ & $192(56.6 \%)$ & 0.105 & NS & 1.738 & NS & 0.414 & NS \\
\hline 8-9 a.m. & $11(4.7 \%)$ & $7(7.0 \%)$ & $27(8.0 \%)$ & 0.742 & NS & 2.421 & NS & 0.101 & NS \\
\hline 9-10 a.m. & $2(0.9 \%)$ & $3(3.0 \%)$ & $3(0.9 \%)$ & - & NS * & - & NS * & - & NS * \\
\hline > 10 a.m. & $2(0.9 \%)$ & $1(1.0 \%)$ & $2(0.6 \%)$ & - & NS * & - & NS * & - & NS * \\
\hline \multicolumn{10}{|c|}{$\begin{array}{l}\text { Risetime WD } \\
\text { during }\end{array}$} \\
\hline$<7$ a.m. & $14(6.1 \%)$ & $19(19.6 \%)$ & $15(4.5 \%)$ & 13.70 & 0.000 & 0.754 & NS & 23.901 & $<0.001$ \\
\hline 7-8 a.m. & $43(18.7 \%)$ & $28(28.9 \%)$ & $90(26.7 \%)$ & 4.152 & 0.042 & 4.886 & 0.027 & 0.177 & NS \\
\hline 8-9 a.m. & $103(44.8 \%)$ & $22(22.7 \%)$ & $144(42.7 \%)$ & 14.11 & $<0.001$ & 0.234 & NS & 12.891 & $<0.001$ \\
\hline 9-10 a.m. & $44(19.1 \%)$ & $16(16.5 \%)$ & $68(20.2 \%)$ & 0.316 & NS & 0.095 & NS & 0.655 & NS \\
\hline >10 a.m. & $26(11.3 \%)$ & $12(12.4 \%)$ & $20(5.9 \%)$ & 0.076 & NS & 5.287 & 0.021 & 4.569 & 0.033 \\
\hline
\end{tabular}

$\mathrm{WD}=$ weekday. Significant differences at $p<0.05$ are in bold. ${ }^{*}$ Fisher's exact test was applied.

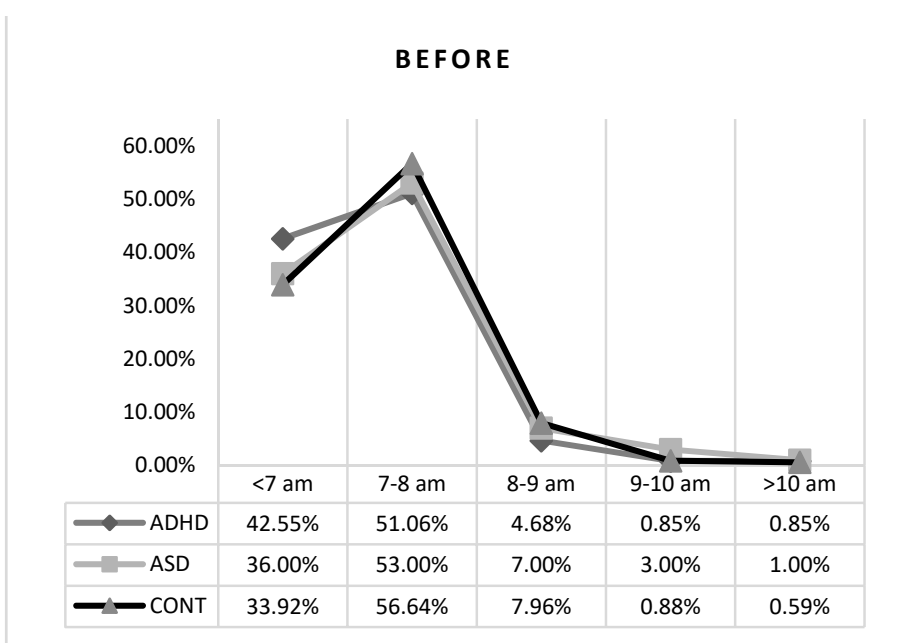

(a)

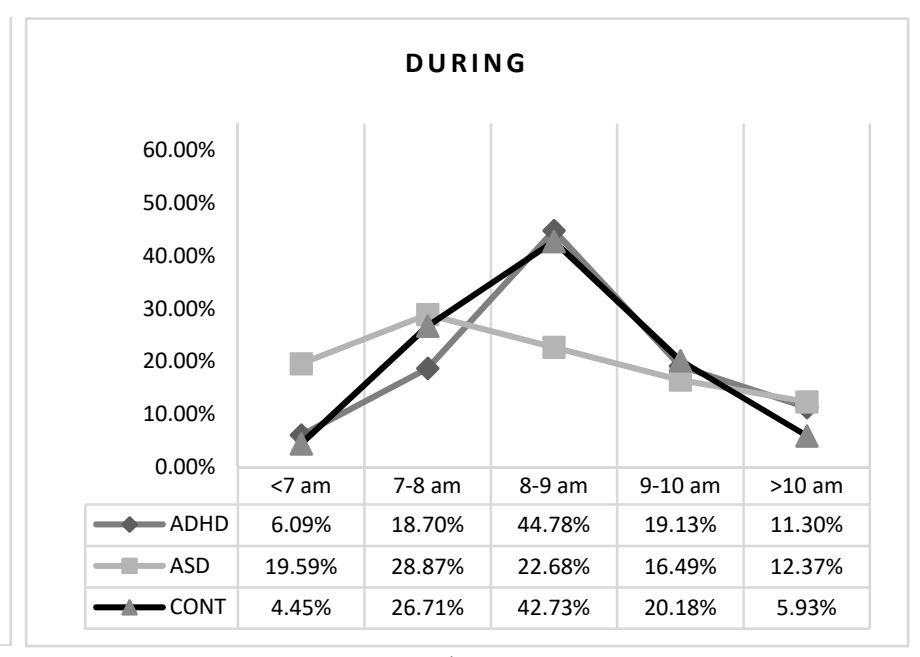

(b)

Figure 2. Risetime before (a) and during (b) lockdown in the tree groups.

\subsubsection{Sleep Duration}

Before lockdown, both clinical groups, when compared to controls, had a significantly higher percentage of children sleeping less than $7 \mathrm{~h}$ (Table 4, Figure 3). Moreover, the ASD group showed a lower percentage of children sleeping between 8 to $9 \mathrm{~h} / \mathrm{night}$ than the ADHD and control groups. 
Table 4. Comparison between sleep duration in weekdays before and during lockdown in the three groups.

\begin{tabular}{|c|c|c|c|c|c|c|c|c|c|}
\hline & \multirow[b]{2}{*}{ ADHD } & \multirow[b]{2}{*}{ ASD } & \multirow[b]{2}{*}{ Controls } & \multicolumn{2}{|c|}{ ADHD vs. ASD } & \multicolumn{2}{|c|}{ ADHD vs. Controls } & \multicolumn{2}{|c|}{ ASD vs. Controls } \\
\hline & & & & $x^{2}$ & $p$ & $\chi^{2}$ & $p$ & $x^{2}$ & $p$ \\
\hline \multicolumn{10}{|c|}{$\begin{array}{l}\text { Sleep duration WD } \\
\text { before }\end{array}$} \\
\hline$<7 \mathrm{~h}$ & $27(11.5 \%)$ & $11(11.2 \%)$ & $16(4.7 \%)$ & 0.005 & NS & 9.241 & 0.002 & 5.588 & 0.018 \\
\hline $7-8 \mathrm{~h}$ & $64(27.2 \%)$ & $36(36.7 \%)$ & $83(24.4 \%)$ & 2.971 & NS & 0.582 & NS & 5.838 & 0.016 \\
\hline $8-9 \mathrm{~h}$ & $94(40.0 \%)$ & $28(28.6 \%)$ & $136(40.0 \%)$ & 3.891 & 0.049 & 0.000 & NS & 4.242 & 0.039 \\
\hline $9-10 \mathrm{~h}$ & $40(17.0 \%)$ & $18(18.4 \%)$ & $74(21.8 \%)$ & 0.087 & NS & 1.967 & NS & 0.529 & NS \\
\hline$>10 \mathrm{~h}$ & $10(4.3 \%)$ & $5(5.1 \%)$ & $31(9.1 \%)$ & 0.115 & NS & 4.961 & 0.026 & 1.626 & NS \\
\hline \multicolumn{10}{|c|}{$\begin{array}{l}\text { Sleep duration WD } \\
\text { during }\end{array}$} \\
\hline$<7 \mathrm{~h}$ & $30(12.8 \%)$ & $20(20.2 \%)$ & $20(5.9 \%)$ & 2.971 & NS & 8.326 & 0.002 & 18.888 & $<0.001$ \\
\hline $7-8 \mathrm{~h}$ & $44(18.8 \%)$ & $24(24.2 \%)$ & $56(16.5 \%)$ & 1.266 & NS & 0.501 & NS & 3.062 & NS \\
\hline $8-9 \mathrm{~h}$ & $88(37.6 \%)$ & $29(29.3 \%)$ & $132(38.9 \%)$ & 2.110 & NS & 0.104 & NS & 3.066 & NS \\
\hline 9-10 h & $55(23.5 \%)$ & $20(20.2 \%)$ & 87 (25.7\%) & 0.435 & NS & 0.347 & NS & 1.238 & NS \\
\hline$>10 \mathrm{~h}$ & $17(7.3 \%)$ & $6(6.1 \%)$ & $44(13.0 \%)$ & 0.157 & NS & 4.752 & 0.029 & 3.627 & NS \\
\hline
\end{tabular}

$\mathrm{WD}=$ weekday. Significant differences at $p<0.05$ are in bold.

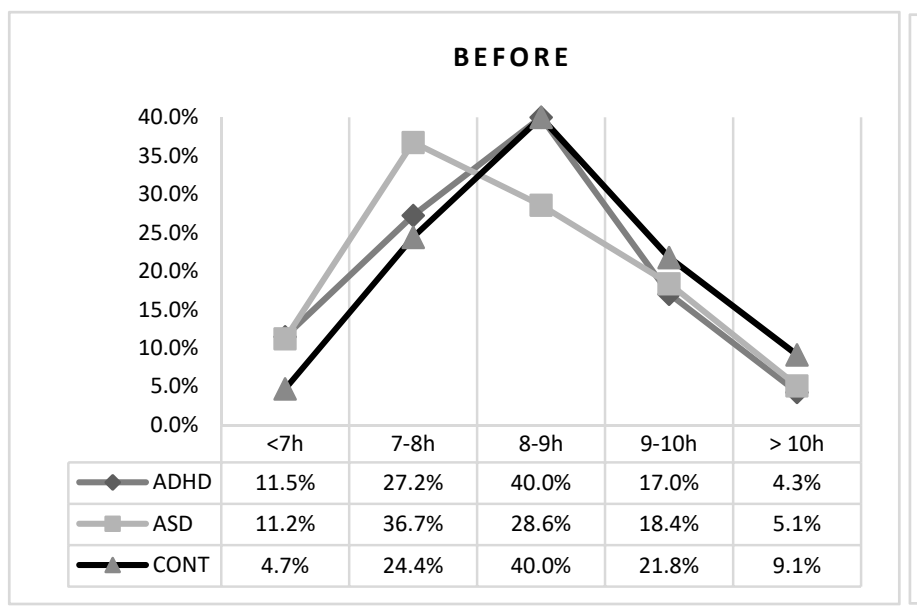

(a)

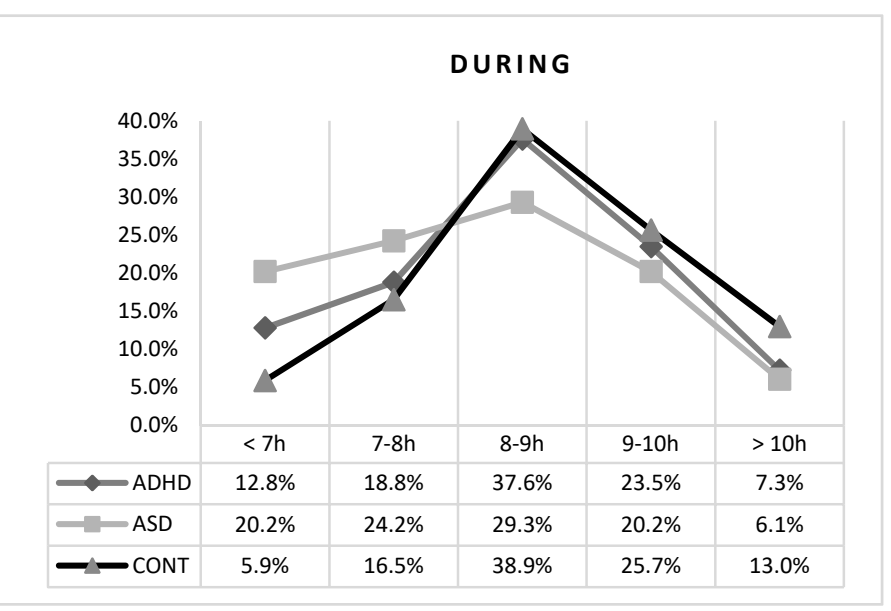

(b)

Figure 3. Sleep duration before (a) and during (b) lockdown in the tree groups.

During lockdown, no differences in sleep duration were found between the two clinical groups while both clinical groups had a significantly higher percentage of children sleeping less than $7 \mathrm{~h}$ than controls (Table 4; Figure 3).

\subsection{Comparison of Sleep Patterns during Lockdown}

ADHD children showed a higher percentage of delaying and a lower percentage of maintaining weekday bedtime than ASD and controls and tended to delay risetime during weekday and weekend more than ASD but not than controls (Table 5). Sleep duration changes were not different between the ADHD and ASD groups, while controls showed a higher percentage of children who maintained the same sleep duration. Compared to controls, both clinical groups increased the weekday and weekend sleep latency during the lockdown (Table 6). 
Table 5. Comparison of weekday-weekend bedtime and risetime in the three groups.

\begin{tabular}{|c|c|c|c|c|c|c|c|c|c|}
\hline & Delayed & Advanced & Maintained & $x^{2}$ & $p$ & $x^{2}$ & $p$ & $x^{2}$ & $p$ \\
\hline \multicolumn{10}{|c|}{ Bedtime WD } \\
\hline ADHD & $188(80.7 \%)$ & 0 & $45(19.3 \%)$ & 19.947 & $<0.001$ & 9.824 & 0.007 & 4.845 & NS \\
\hline ASD & $58(58 \%)$ & $1(1 \%)$ & $41(41 \%)$ & & & & & & \\
\hline Controls & $235(69.7 \%)$ & $3(0.9 \%)$ & $99(29.4 \%)$ & & & & & & \\
\hline \multicolumn{10}{|c|}{ Bedtime WE } \\
\hline ADHD & $98(42.4 \%)$ & $5(2.2 \%)$ & $128(55.4 \%)$ & 2.280 & NS & 5.621 & NS & 1.875 & NS \\
\hline ASD & $44(44.4 \%)$ & $5(5.1 \%)$ & $50(50.5)$ & & & & & & \\
\hline Controls & $124(36.8 \%)$ & $20(5.9 \%)$ & $193(57.3 \%)$ & & & & & & \\
\hline \multicolumn{10}{|c|}{ Risetime WD } \\
\hline ADHD & $192(81.4 \%)$ & $3(1.3 \%)$ & $34(14.8 \%)$ & 22.444 & $<0.001$ & 6.602 & NS & 20.606 & $<0.001$ \\
\hline ASD & $59(60.8 \%)$ & $7(7.2 \%)$ & $31(32 \%)$ & & & & & & \\
\hline Controls & $256(76.2 \%)$ & $2(0.6 \%)$ & $78(23.2 \%)$ & & & & & & \\
\hline \multicolumn{10}{|c|}{ Risetime WE } \\
\hline ADHD & $136(58.6 \%)$ & $41(17.7 \%)$ & $55(23.7 \%)$ & 33.333 & $<0.001$ & 2.199 & NS & 43.600 & $<0.001$ \\
\hline ASD & $31(31 \%)$ & $13(13 \%)$ & $56(56 \%)$ & & & & & & \\
\hline Controls & $216(63.9 \%)$ & $46(13.6 \%)$ & $76(22.5 \%)$ & & & & & & \\
\hline
\end{tabular}

$\mathrm{WD}=$ weekday; $\mathrm{WE}=$ weekend. Significant differences at $p<0.05$ are in bold.

Table 6. Comparison of weekday-weekend sleep duration and sleep latency in the three groups.

\begin{tabular}{|c|c|c|c|c|c|c|c|c|c|}
\hline & \multirow[b]{2}{*}{ Increased } & \multirow[b]{2}{*}{ Decreased } & \multirow[b]{2}{*}{ Maintained } & \multicolumn{2}{|c|}{ ADHD vs. ASD } & \multicolumn{2}{|c|}{ ADHD vs. Controls } & \multicolumn{2}{|c|}{ ASD vs. Controls } \\
\hline & & & & $x^{2}$ & $p$ & $x^{2}$ & $p$ & $\chi^{2}$ & $p$ \\
\hline \multicolumn{10}{|c|}{$\begin{array}{l}\text { Sleep duration } \\
\text { WD }\end{array}$} \\
\hline ADHD & $80(34.3 \%)$ & $59(25.3 \%)$ & $94(40.3 \%)$ & 5.318 & NS & 16.165 & $<0.001$ & 7.214 & 0.027 \\
\hline ASD & $22(22.4 \%)$ & $25(25.5 \%)$ & $51(52 \%)$ & & & & & & \\
\hline Controls & $101(29.8 \%)$ & $49(14.4 \%)$ & $189(55.8 \%)$ & & & & & & \\
\hline \multicolumn{10}{|c|}{$\begin{array}{l}\text { Sleep duration } \\
\text { WE }\end{array}$} \\
\hline ADHD & $49(21.3 \%)$ & $51(22.2 \%)$ & $130(56.5 \%)$ & 0.914 & NS & 24.650 & $<0.001$ & 22.627 & $<0.001$ \\
\hline ASD & $17(17 \%)$ & $25(25 \%)$ & $58(58 \%)$ & & & & & & \\
\hline Controls & $78(23.1)$ & $26(7.7 \%)$ & $233(69.2 \%)$ & & & & & & \\
\hline \multicolumn{10}{|c|}{ Sleep latency } \\
\hline ADHD & $103(48.4 \%)$ & $0(0 \%)$ & $110(51.6 \%)$ & 5.195 & NS & 7.190 & 0.027 & 12.058 & 0.002 \\
\hline ASD & $41(57.7 \%)$ & $1(1.4 \%)$ & $29(40.8 \%)$ & & & & & & \\
\hline Controls & $116(31.1 \%)$ & $1(0.3 \%)$ & $196(62.6 \%)$ & & & & & & \\
\hline \multicolumn{10}{|c|}{ Sleep latency } \\
\hline ADHD & $117(51.6 \%)$ & $2(0.9 \%)$ & $110(48.0 \%)$ & 4.181 & NS & 9.416 & 0.009 & 14.101 & $<0.001$ \\
\hline ASD & $49(61.3 \%)$ & $2(2.5 \%)$ & $29(36.3 \%)$ & & & & & & \\
\hline Controls & $127(38.5)$ & $7(2.1 \%)$ & $196(59.4 \%)$ & & & & & & \\
\hline
\end{tabular}

$\mathrm{WD}=$ weekday; $\mathrm{WE}=$ weekend. Significant differences at $p<0.05$ are in bold.

3.3. Comparison of the Prevalence of Sleep Disorders in the Three Groups before and during Lockdown

3.3.1. Intragroup Comparison

During lockdown, we observed an increased prevalence of several sleep disorders, especially in the two clinical groups (Supplementary Table S1).

A significant increase in anxiety at bedtime and daytime sleepiness was found in all the three groups: anxiety at bedtime increased from $15.3 \%$ to $23.7 \%$ in ADHD children $(p=0.007)$, from $12.0 \%$ to $22.0 \%$ in the ASD group $(p=0.006)$, and from 5.6 to $11.2 \%$ in controls $(p=0.003)$.

Difficulty in falling asleep increased in the two clinical groups: from $27.1 \%$ to $39.0 \%$ in the ADHD group $(p=0.001)$, and from $23.0 \%$ to $35.0 \%$ in the ASD group $(p=0.029)$. 
Prevalence of sleepwalking increased significantly only in the ADHD and control groups, from $0.4 \%$ to $5.9 \%(p=0.000)$ for ADHD and from $0.0 \%$ to $2.4 \%(p=0.000)$ for controls.

Nightmares increased in all the three groups but significantly only in controls, from $4.7 \%$ to $10.3 \%(p=0.003)$. Daytime sleepiness increased from $12.3 \%$ to $19.9 \%$ in the ADHD group ( $p=0.005)$, from $4.0 \%$ to $15.0 \%$ in the ASD group $(p=0.003)$ and from $4.4 \%$ to $7.9 \%$ in the control group $(p=0.029)$.

The only significant decrease in sleep disorders was found for bruxism in ADHD children that diminished from $16.5 \%$ to $11.0 \%(p=0.015)$.

\subsubsection{Intergroup Comparison}

While before lockdown there was no difference between the clinical groups and controls, during lockdown difficulties in falling asleep significantly increased in the two clinical groups resulting in a significant difference with the control group.

Anxiety at bedtime, hypnic jerks, rhythmic movement disorder, and night awakenings were found to be significantly higher in the clinical groups than in controls, both before and during lockdown.

Restless sleep and snoring/apnea were significantly higher in both clinical groups than in controls (in ASD, only during lockdown) (Table 7).

Table 7. Comparison of sleep disorders before and during lockdown in the three groups.

\begin{tabular}{|c|c|c|c|c|c|c|c|c|c|c|}
\hline & & \multirow[b]{2}{*}{ ADHD \% } & \multirow[b]{2}{*}{ ASD \% } & \multirow[b]{2}{*}{ CONT \% } & \multicolumn{2}{|c|}{ ADHD vs. ASD } & \multicolumn{2}{|c|}{ ADHD vs. Control } & \multicolumn{2}{|c|}{ ASD vs. Control } \\
\hline & & & & & $x^{2}$ & $p$ & $x^{2}$ & $p$ & $x^{2}$ & $p$ \\
\hline \multirow[t]{2}{*}{ Difficulties falling asleep } & before & $64(27.1 \%)$ & $23(23.0 \%)$ & $72(21.2 \%)$ & 0.621 & NS & 2.727 & NS & 0.152 & NS \\
\hline & during & $92(39.0 \%)$ & $35(35.0 \%)$ & $65(19.1 \%)$ & 0.474 & NS & 27.726 & $<0.001$ & 11.099 & 0.001 \\
\hline \multirow[t]{2}{*}{ Anxiety at bedtime } & before & $36(15.3 \%)$ & $12(12.0 \%)$ & $19(5.6 \%)$ & 0.607 & NS & 15.070 & $<0.001$ & 4.831 & 0.028 \\
\hline & during & $56(23.7 \%)$ & $22(22.0 \%)$ & $38(11.2 \%)$ & 0.118 & NS & 16.073 & $<0.001$ & 7.687 & 0.006 \\
\hline \multirow[t]{2}{*}{ Hypnic jerks } & before & $30(12.7 \%)$ & $11(11.0 \%)$ & $14(4.1 \%)$ & 0.192 & NS & 14.583 & $<0.001$ & 6.830 & 0.009 \\
\hline & during & $39(16.5 \%)$ & $12(12.0 \%)$ & $13(3.8 \%)$ & 1.117 & NS & 27.366 & $<0.001$ & 9.640 & 0.002 \\
\hline \multirow[t]{2}{*}{ Rhythmic movement dis. } & before & $10(4.2 \%)$ & $7(7.0 \%)$ & $5(1.5 \%)$ & 1.116 & NS & 4.204 & 0.040 & 8.906 & 0.003 \\
\hline & during & $14(5.9 \%)$ & $9(9.0 \%)$ & $7(2.1 \%)$ & 1.037 & NS & 5.950 & 0.015 & 10.625 & 0.001 \\
\hline \multirow[t]{2}{*}{ Night awakenings $>2$} & before & $29(12.3 \%)$ & $10(10.0 \%)$ & $11(3.2 \%)$ & 0.358 & NS & 17.667 & 0.000 & 7.780 & 0.005 \\
\hline & during & $34(14.4 \%)$ & $18(18.0 \%)$ & $21(6.2 \%)$ & 0.693 & NS & 10.926 & 0.001 & 13.373 & 0.000 \\
\hline \multirow[t]{2}{*}{ Restless sleep } & before & $80(33.9 \%)$ & $28(28.0 \%)$ & $75(22.1 \%)$ & 1.120 & NS & 9.928 & 0.002 & 1.521 & NS \\
\hline & during & $83(35.2 \%)$ & $34(34.0 \%)$ & $71(20.9 \%)$ & 0.042 & NS & 14.517 & 0.000 & 7.318 & 0.007 \\
\hline \multirow[t]{2}{*}{ Snoring/apneas } & before & $19(8.1 \%)$ & $8(8.0 \%)$ & $13(3.8 \%)$ & 0.000 & NS & 4.745 & 0.029 & 2.966 & NS \\
\hline & during & $22(9.3 \%)$ & $9(9.0 \%)$ & $12(3.5 \%)$ & 0.009 & NS & 8.416 & 0.004 & 5.088 & 0.024 \\
\hline \multirow[t]{2}{*}{ Sleepwalking } & before & $1(0.4 \%)$ & $3(3.0 \%)$ & $0(0.0 \%)$ & - & NS * & - & NS * & - & 0.011 * \\
\hline & during & $14(5.9 \%)$ & $7(7.0 \%)$ & $8(2.4 \%)$ & 0.137 & NS & 4.858 & 0.028 & 5.068 & 0.024 \\
\hline \multirow[t]{2}{*}{ Sleep terrors } & before & $3(1.3 \%)$ & $0(0.0 \%)$ & $4(1.2 \%)$ & - & NS * & - & NS * & - & NS * \\
\hline & during & $4(1.7 \%)$ & $4(4.0 \%)$ & $2(0.6 \%)$ & - & NS * & - & NS * & - & $0.026^{*}$ \\
\hline \multirow[t]{2}{*}{ Bruxism } & before & $39(16.5 \%)$ & $7(7.0 \%)$ & $31(9.1 \%)$ & 5.393 & 0.020 & 7.160 & 0.007 & 0.439 & NS \\
\hline & during & $26(11.0 \%)$ & $11(11.0 \%)$ & $21(6.2 \%)$ & 0.000 & NS & 4.355 & 0.037 & 2.666 & NS \\
\hline \multirow[t]{2}{*}{ Nightmares } & before & $28(11.9 \%)$ & $2(2.0 \%)$ & $16(4.7 \%)$ & - & 0.003 * & 10.118 & 0.001 & - & NS * \\
\hline & during & $42(17.8 \%)$ & $5(5.0 \%)$ & $35(10.3 \%)$ & 9.560 & 0.002 & 6.771 & 0.009 & 2.621 & NS \\
\hline \multirow[t]{2}{*}{ Daytime sleepiness } & before & $29(12.3 \%)$ & $4(4.0 \%)$ & $15(4.4 \%)$ & - & 0.026 * & 12.249 & 0.000 & - & NS * \\
\hline & during & $47(19.9 \%)$ & $15(15.0 \%)$ & $27(7.9 \%)$ & 1.128 & NS & 17.839 & 0.000 & 4.459 & 0.035 \\
\hline
\end{tabular}

Significant differences at $p<0.05$ are in bold. ${ }^{*}$ Fisher's exact test was applied.

Compared to controls, sleepwalking was more prevalent in the ASD group, both before and during lockdown, while sleep terrors were more prevalent only during lockdown.

The prevalence of bruxism and nightmares was significantly increased in children with ADHD compared to ASD and controls, both before and during lockdown.

On the other hand, no differences were found between ASD and controls in the prevalence of nightmares and bruxism (Table 7).

Daytime sleepiness was higher in ADHD than in control children, both before and during lockdown, and slightly more prevalent in ASD than in controls during lockdown (Table 7; Figures S1 and S2). 


\section{Discussion}

The lockdown experience significantly impacted sleep patterns and disturbances of children and adolescents with ADHD and ASD, as well as of controls. As also indicated by other studies [5,6,12], sleep is one of the more impaired domains during the COVID-19 lockdown, independently by mental health condition and age and it is known that sleep problems in ASD and ADHD patients may worsen daytime behavior and functioning, as well as increase parental distress [11]. We found, in both clinical groups, a higher percentage of subjects that reported a reduced sleep duration and an increased sleep latency than controls. ASD patients showed less changes in weekday-weekend risetime than both ADHD and controls, while children with ADHD reported higher delays in bedtime than the other groups. Our findings are supported by specific studies on these two clinical groups and controls [2,16], reporting delayed bedtime in children with ADHD [10,17] and a reduced sleep duration in both ADHD and ASD [9,10,13,15,22].

Although changes of lifestyle caused by the lockdown affected both clinical groups and controls, generally children and adolescents with ADHD showed greater instability of their sleep schedule and increased delay in weekday sleep schedule, when compared to ASD and controls, during lockdown. This finding, according to the night-to-night variability in the sleep-wake patterns reported by several comparative studies in children with ADHD compared to typically developing children [23-25], supports the consideration that the "variability" of sleep patterns, represents a distinctive marker of the ADHD condition.

Since ADHD patients' functioning is strongly dependent on environmental changes, in agreement with other studies $[10,26]$, our findings confirm that sudden lifestyle changes caused by the pandemic lockdown impacted the sleep and behavior of ADHD patients more than on those of ASD patients or controls. Conversely, children and adolescents with ASD seemed to be less vulnerable to the effects of prolonged isolation, showing a higher stability in bedtime and risetime than both ADHD and controls, probably linked to the stereotyped and fixed behavior of these children, since inflexibility and insistence on sameness are hallmark characteristics of ASD [15].

The significantly decreased sleep duration in the ADHD group, compared to controls, is supported by the study by Becker et al. [13], suggesting that ADHD patients did not benefit from the COVID-19 lockdown, unlike their healthy peers of the control group that experienced an increase in school days night sleep duration and were more likely to obtain recommended sleep duration during COVID-19. Similarly, Mutluer et al. [15] reported a decrease in the number of hours ASD children slept from before to during COVID-19. Finally, our findings agree with those by Bruni et al. [2] who reported a general stable sleep duration among healthy children, with only a small but significant increase during lockdown.

We found an increase in several sleep disorders during the lockdown: some disorders increased in all the three groups, such as anxiety at bedtime and daytime sleepiness while difficulties in falling asleep hypnic jerks, rhythmic movement disorder, night awakenings, restless sleep, sleepwalking, and daytime sleepiness increased especially in patients with ASD and ADHD. Interestingly, at baseline, ADHD children resulted to have increased bruxism, nightmares, and daytime sleepiness than their ASD peers, while during the lockdown ASD and ADHD children and adolescents had a similar prevalence of all sleep disturbances, with the exception of nightmares that were more frequent in ADHD children.

Very few studies have been published on the impact of the COVID-19 lockdown on sleep disorders of patients with ASD and ADHD. Regarding the sleep disorders of ASD patients during the pandemic, our results are in agreement with those by Türkoğlu et al. [17] that reported an increase in difficulties (and delay) in falling asleep, and anxiety at bedtime; in contrast, we did not find an increase in night awakenings, but we observed an increase in daytime sleepiness. Similarly, Lugo-Marin et al. [14] reported a deterioration in sleep quality in $56 \%$ of 100 ASD patients (children and adults). Very few studies have examined sleep disorders of ADHD youths during COVID-19. In a sample of 241 youth (aged 6-15 years) with ADHD in China, $48 \%$ of parents indicated that COVID-19 had not changed 
their child's sleep, with $20 \%$ indicating that sleep had worsened, and $32 \%$ indicating that sleep had improved. Becker et al. [13] reported less improvement of daytime sleepiness in ADHD adolescents compared to their healthy peers of the control group.

Several sleep symptoms that we found increased in our ASD and ADHD children have been recognized to be an expression of a psychological distress condition $[27,28]$ strictly related to the pandemic.

Altogether, our findings confirm a great distress susceptibility in both clinical children due to the sudden changes of lifestyle imposed by the lockdown experience that determined a vulnerability of their sleep-wake patterns. The different sleep pattern alterations in the two clinical groups might be linked to their core traits defining two distinct disorders: children with ASD, that tended to maintain their sleep-wake schedule, were less vulnerable due to the stereotyped behavior and insistence on sameness while children with ADHD, that showed greater changes in sleep-wake patterns, were more vulnerable, due to their innate behavior instability, swift changes in mood, and low frustration tolerance.

We have to consider that the interruption of social relationships, the reduction in physical activities as well as the academic and normal working activities, had an impact on sleep. In parallel, other studies showed a strong impact of lockdown on affective domains, highlighting mainly an increase in depression symptoms (for ADHD see Melegari et al., 2021) [26]. Further studies focused on the lockdown impact on both sleep patterns and affective states in these clinical populations should contribute to explain their reciprocal interaction. Some limitations of this study need to be considered, such as the sample size (although relatively large for this condition) and sampling only respondents from a single country; thus, results may not be fully generalizable to other countries. In addition, the predetermined sample size to adequately reduce the risk of type II error was not achieved. Furthermore, most subjectively reported elements of the SDSC should be interpreted with caution due to potential parental misinterpretation in ASD subjects that are often nonverbal. Although the survey was conducted after only a few days from the end of the strict lockdown and in the presence of lighter restrictions, we cannot exclude a memory bias of the parents. Finally, we should consider that self-selection bias is inherent with the online survey methodology employing nonprobability sampling. On the other hand, a strength of the study is that examined similarity or differences in sleep pattern changes using the same instruments and the same temporal window of investigation.

\section{Conclusions}

To our knowledge, this is the first study comparing sleep habits and disorders in two neurodevelopmental disorders, ASD and ADHD, highlighting the differences in sleep patterns and disorders between these two different clinical populations, both at baseline and during the COVID-19 lockdown. It will be important to examine whether changes in sleep persist over time, continue to change, or return to the pre-COVID-19 levels as the pandemic continues.

Supplementary Materials: The following are available online at https:/ /www.mdpi.com/article/10 $.3390 /$ brainsci11091139/s1, Supplementary Table S1. Sleep disorders before and during lockdown in the three groups. Figure S1: Sleep disorders in the three groups before lockdown, Figure S2: Sleep disorders in the three groups during lockdown.

Author Contributions: Conceptualization, O.B., M.B., R.F. and M.G.M.; data curation, O.B., M.B. and M.G.M.; formal analysis, O.B., M.B., R.F. and M.G.M.; methodology, O.B., M.B., R.F. and M.G.M.; supervision, O.B., R.F. and M.G.M.; writing—original draft, O.B., M.B. and M.G.M.; writing-review and editing, O.B., M.B., R.F. and M.G.M. All authors have read and agreed to the published version of the manuscript.

Funding: This research received no external funding.

Institutional Review Board Statement: The study was conducted according to the guidelines of the Declaration of Helsinki, and approved by the Institutional Review Board (or Ethics Committee) of 
Department of Developmental and Social Psychology, Sapienza University, Rome (protocol code 451, $14 / 04 / 2021$.

Informed Consent Statement: Informed consent was obtained from all subjects involved in the study.

Data Availability Statement: This study was not preregistered, and the data that support the findings of this study are available on request from the corresponding author (O.B.). The data are not publicly available due to restrictions, e.g., containing information that could compromise the privacy of research participants.

Acknowledgments: The authors gratefully acknowledge all parents who have participated to the survey allowing to the study to be carried out.

Conflicts of Interest: The authors declare no conflict of interest.

\section{References}

1. Singh, S.; Roy, D.; Sinha, K.; Parveen, S.; Sharma, G.; Joshi, G. Impact of COVID-19 and Lockdown on Mental Health of Children and Adolescents: A Narrative Review with Recommendations. Psychiatry Res. 2020, 293, 113429. [CrossRef]

2. Bruni, O.; Malorgio, E.; Doria, M.; Finotti, E.; Spruyt, K.; Melegari, M.G.; Villa, M.P.; Ferri, R. Changes in Sleep Patterns and Disturbances in Children and Adolescents in Italy during the Covid-19 Outbreak. Sleep Med. 2021. [CrossRef]

3. Cellini, N.; Canale, N.; Mioni, G.; Costa, S. Changes in Sleep Pattern, Sense of Time and Digital Media Use during COVID-19 Lockdown in Italy. J. Sleep Res. 2020, 29, e13074. [CrossRef] [PubMed]

4. Innocenti, P.; Puzella, A.; Mogavero, M.P.; Bruni, O.; Ferri, R. Letter to Editor: CoVID-19 Pandemic and Sleep Disorders-A Web Survey in Italy. Neurol. Sci. 2020, 41, 2021-2022. [CrossRef] [PubMed]

5. Liu, Z.; Tang, H.; Jin, Q.; Wang, G.; Yang, Z.; Chen, H.; Yan, H.; Rao, W.; Owens, J. Sleep of Preschoolers during the Coronavirus Disease 2019 (COVID-19) Outbreak. J. Sleep Res. 2021, 30, e13142. [CrossRef] [PubMed]

6. Moore, S.A.; Faulkner, G.; Rhodes, R.E.; Brussoni, M.; Chulak-Bozzer, T.; Ferguson, L.J.; Mitra, R.; O’Reilly, N.; Spence, J.C.; Vanderloo, L.M.; et al. Impact of the COVID-19 Virus Outbreak on Movement and Play Behaviours of Canadian Children and Youth: A National Survey. Int. J. Behav. Nutr. Phys. Act. 2020, 17, 85. [CrossRef]

7. Khubchandani, J.; Sharma, S.; Webb, F.J.; Wiblishauser, M.J.; Bowman, S.L. Post-Lockdown Depression and Anxiety in the USA during the COVID-19 Pandemic. J. Public Health Oxf. Engl. 2021, fdaa250. [CrossRef]

8. Scarpelli, S.; Alfonsi, V.; Mangiaruga, A.; Musetti, A.; Quattropani, M.C.; Lenzo, V.; Freda, M.F.; Lemmo, D.; Vegni, E.; Borghi, L.; et al. Pandemic Nightmares: Effects on Dream Activity of the COVID-19 Lockdown in Italy. J. Sleep Res. 2021, e13300. [CrossRef]

9. Bruni, O.; Melegari, M.G.; Breda, M.; Cedrone, A.; Finotti, E.; Malorgio, E.; Doria, M.; Ferri, R. Impact of COVID-19 Lockdown on Sleep in Children with Autism Spectrum Disorders. J. Clin. Sleep Med. JCSM Off. Publ. Am. Acad. Sleep Med. 2021, 9518. [CrossRef]

10. Bruni, O.; Giallonardo, M.; Sacco, R.; Ferri, R.; Melegari, M.G. The Impact of Lockdown on Sleep Patterns of Children and Adolescents with ADHD. J. Clin. Sleep Med. JCSM Off. Publ. Am. Acad. Sleep Med. 2021. [CrossRef]

11. Singh, K.; Zimmerman, A.W. Sleep in Autism Spectrum Disorder and Attention Deficit Hyperactivity Disorder. Semin. Pediatr. Neurol. 2015, 22, 113-125. [CrossRef] [PubMed]

12. Pietrobelli, A.; Pecoraro, L.; Ferruzzi, A.; Heo, M.; Faith, M.; Zoller, T.; Antoniazzi, F.; Piacentini, G.; Fearnbach, S.N.; Heymsfield, S.B. Effects of COVID-19 Lockdown on Lifestyle Behaviors in Children with Obesity Living in Verona, Italy: A Longitudinal Study. Obes. Silver Spring Md. 2020, 28, 1382-1385. [CrossRef] [PubMed]

13. Becker, S.P.; Dvorsky, M.R.; Breaux, R.; Cusick, C.N.; Taylor, K.P.; Langberg, J.M. Prospective Examination of Adolescent Sleep Patterns and Behaviors Before and During COVID-19. Sleep 2021, 44, 54. [CrossRef] [PubMed]

14. Lugo Marín, J.; Gisbert Gustemps, L.; Setien Ramos, I.; Español Martín, G.; Ibañez Jimenez, P.; Forner Puntonet, M.; ArteagaHenríquez, G.; Soriano Día, A.; Duque Yemail, J.D.; Ramos Quiroga, J.A. COVID-19 Pandemic Effects in People with Autism Spectrum Disorder and Their Caregivers: Evaluation of Social Distancing and Lockdown Impact on Mental Health and General Status. Res. Autism. Spectr. Disord. 2021, 83, 101757. [CrossRef] [PubMed]

15. Mutluer, T.; Doenyas, C.; Aslan Genc, H. Behavioral Implications of the Covid-19 Process for Autism Spectrum Disorder, and Individuals' Comprehension of and Reactions to the Pandemic Conditions. Front. Psychiatry 2020, 11. [CrossRef]

16. Navarro Soria, I.; Real Fernández, M.; Juárez-Ruiz de Mier, R.; Costa López, B.; Sánchez-Muñoz de León, M.; Lavigne Cerván, R. Consequences of Confinement Due to COVID-19 in Spain on Anxiety, Sleep and Executive Functioning of Children and Adolescents with ADHD. Sustainability 2021, 13, 2487. [CrossRef]

17. Türkoğlu, S.; Uçar, H.N.; Çetin, F.H.; Güler, H.A.; Tezcan, M.E. The Relationship between Chronotype, Sleep, and Autism Symptom Severity in Children with ASD in COVID-19 Home Confinement Period. Chronobiol. Int. 2020, 37, 1207-1213. [CrossRef]

18. Eysenbach, G. Improving the Quality of Web Surveys: The Checklist for Reporting Results of Internet E-Surveys (CHERRIES). J. Med. Internet Res. 2004, 6, e132. [CrossRef]

19. Bruni, O.; Ottaviano, S.; Guidetti, V.; Romoli, M.; Innocenzi, M.; Cortesi, F.; Giannotti, F. The Sleep Disturbance Scale for Children (SDSC) Construction and Validation of an Instrument to Evaluate Sleep Disturbances in Childhood and Adolescence. J. Sleep Res. 1996, 5, 251-261. [CrossRef] 
20. Romeo, D.; Bruni, O.; Brogna, C.; Ferri, R.; Galluccio, C.; Clemente, V.; Jorio, M.; Quintiliani, M.; Ricci, D.; Mercuri, E. Application of the Sleep Disturbance Scale for Children (SDSC) in Preschool Age. Eur. J. Paediatr. Neurol. EJPN Off. J. Eur. Paediatr. Neurol. Soc. 2013, 17, 374-382. [CrossRef]

21. Romeo, D.M.; Cordaro, G.; Macchione, E.; Venezia, I.; Brogna, C.; Mercuri, E.; Bruni, O. Application of the Sleep Disturbance Scale for Children (SDSC) in Infants and Toddlers (6-36 Months). Sleep Med. 2021, 81, 62-68. [CrossRef]

22. Berard, M.; Rattaz, C.; Peries, M.; Loubersac, J.; Munir, K.; Baghdadli, A. Impact of Containment and Mitigation Measures on Children and Youth with ASD during the COVID-19 Pandemic: Report from the ELENA Cohort. J. Psychiatr. Res. 2021, 137, 73-80. [CrossRef]

23. Gruber, R.; Sadeh, A.; Raviv, A. Instability of Sleep Patterns in Children with Attention-Deficit/Hyperactivity Disorder. J. Am. Acad. Child Adolesc. Psychiatry 2000, 39, 495-501. [CrossRef] [PubMed]

24. Hvolby, A.; Jørgensen, J.; Bilenberg, N. Actigraphic and Parental Reports of Sleep Difficulties in Children with AttentionDeficit/Hyperactivity Disorder. Arch. Pediatr. Adolesc. Med. 2008, 162, 323-329. [CrossRef] [PubMed]

25. Melegari, M.G.; Vittori, E.; Mallia, L.; Devoto, A.; Lucidi, F.; Ferri, R.; Bruni, O. Actigraphic Sleep Pattern of Preschoolers With ADHD. J. Atten. Disord. 2020, 24, 611-624. [CrossRef]

26. Melegari, M.G.; Giallonardo, M.; Sacco, R.; Marcucci, L.; Orecchio, S.; Bruni, O. Identifying the Impact of the Confinement of Covid-19 on Emotional-Mood and Behavioural Dimensions in Children and Adolescents with Attention Deficit Hyperactivity Disorder (ADHD). Psychiatry Res. 2021, 296, 113692. [CrossRef] [PubMed]

27. Biggs, Q.M.; Ursano, R.J.; Wang, J.; Wynn, G.H.; Carr, R.B.; Fullerton, C.S. Post Traumatic Stress Symptom Variation Associated with Sleep Characteristics. BMC Psychiatry 2020, 20, 174. [CrossRef]

28. Milanak, M.E.; Zuromski, K.L.; Cero, I.; Wilkerson, A.K.; Resnick, H.S.; Kilpatrick, D.G. Traumatic Event Exposure, Posttraumatic Stress Disorder, and Sleep Disturbances in a National Sample of U.S. Adults: Trauma Exposure, PTSD, and Sleep. J. Trauma. Stress 2019, 32, 14-22. [CrossRef] [PubMed] 